\title{
Refletindo sobre o uso dos mapas conceituais com CmapTools na formação continuada de professores da educação básica
}

\author{
Reflecting on the use of concept maps with CmapTools in the continuing education of basic \\ education teachers
}

Reflexionar sobre el uso de mapas conceptuales con CmapTools en la formación continua de
docentes de educación básica Recebido: 11/08/2021 | Revisado: 22/08/2021 | Aceito: 24/08/2021 | Publicado: 25/08/2021

Karinna Ribeiro Dantas

ORCID: https://orcid.org/0000-0001-9790-3481 Universidade Federal do Rio Grande do Norte, Brasil E-mail: kkrdantas10@hotmail.com Clécio Danilo Dias da Silva

ORCID: https://orcid.org/0000-0002-7776-8830 Universidade Federal do Rio Grande do Norte, Brasil E-mail: danilodiass18@gmail.com

Karen Christina Pinheiro dos Santos

ORCID: https://orcid.org/0000-0002-6353-9885 Secretaria Municipal de Educação do Município de Natal, Brasil E-mail: karensantos199@hotmail.com Elinei Araújo-de-Almeida

ORCID: https://orcid.org/0000-0003-1617-5641 Universidade Federal do Rio Grande do Norte, Brasil E-mail: elineiaraujo@yahoo.com.br

\begin{abstract}
Resumo
Apesar dos benefícios proporcionados pelos Mapas Conceituais (MCs) no processo de ensino e aprendizagem é notório que, muitas das vezes, esta ferramenta é pouco conhecida e utilizada em sala de aula pelos professores da Educação Básica. Assim, esse artigo teve como objetivos avaliar e refletir sobre a aplicação de uma ação didática sobre MCs e CmapTools, para professores de educação básica, com fins de promover e ampliar conhecimentos sobre essas ferramentas de apoio pedagógico. A ação envolveu uma atividade participativa estruturada em quatro momentos: i) Aplicação do questionário inicial; ii) Exposição dialógica sobre a Teoria da Aprendizagem significativa e Mapas Conceituais; iii) Demonstrações sobre a operacionalização do CmapTools; e iv) Aplicação do questionário final. Os dados obtidos por meio dos questionários e dos registros de relatos espontâneos colocados revelaram carência dos participantes nesses elementos pedagógicos abordados, mas, ao mesmo tempo, foi observado um grande interesse pelo tema associado ao desejo de obter mais aprofundamentos teóricos e práticos sobre os MCs e sua utilização em sala de aula.

Palavras-chave: Formação de professores; Recursos educacionais digitais; Software CmapTools; Oficina pedagógica; Processo de ensino e aprendizagem.
\end{abstract}

\begin{abstract}
Despite the benefits provided by Concept Maps (MCs) in the teaching and learning process, it is clear that this tool is often little known and used in the classroom by Basic Education teachers. Thus, this article aimed to evaluate and reflect on the application of a didactic action on MCs and CmapTools, for basic education teachers, in order to promote and expand knowledge about these pedagogical support tools. The action involved a participatory activity structured in four stages: i) Application of the initial questionnaire; ii) Dialogical exposition on the Theory of Meaningful Learning and Concept Maps; iii) Demonstrations on the operation of CmapTools; and iv) Application of the final questionnaire. The data obtained through the questionnaires and records of spontaneous reports placed revealed a lack of participants in these pedagogical elements addressed, but, at the same time, there was a great interest in the topic associated with the desire to obtain more theoretical and practical insights into the MCs and its use in the classroom.
\end{abstract}

Keywords: Teacher training; Digital educational resources; CmapTools Software; Pedagogical workshop; Teaching and learning process. 


\begin{abstract}
Resumen
A pesar de los beneficios que brindan los Mapas Conceptuales (MCs) en el proceso de enseñanza y aprendizaje, es evidente que esta herramienta suele ser poco conocida y utilizada en el aula por los docentes de Educación Básica. Así, este artículo tuvo como objetivo evaluar y reflexionar sobre la aplicación de una acción didáctica sobre MCs y CmapTools, para docentes de educación básica, con el fin de promover y ampliar el conocimiento sobre estas herramientas de apoyo pedagógico. La acción involucró una actividad participativa estructurada en cuatro etapas: i) Aplicación del cuestionario inicial; ii) Exposición dialógica sobre la Teoría del Aprendizaje Significativo y Mapas Conceptuales; iii) Demostraciones sobre el funcionamiento de CmapTools; y iv) Aplicación del cuestionario final. Los datos obtenidos a través de los cuestionarios y registros de informes espontáneos colocados revelaron una falta de participantes en estos elementos pedagógicos abordados, pero, al mismo tiempo, hubo un gran interés en el tema asociado al deseo de obtener una mayor comprensión teórica y práctica de la temática. los MCs y su uso en el aula.
\end{abstract}

Palabras clave: Formación docente; Recursos educativos digitales; Software CmapTools; Taller Pedagógico; Proceso de enseñanza y aprendizaje.

\title{
1. Introdução
}

Dentro da realidade educacional estabelecida nas escolas de Ensino Básico, ainda é possível se constatar na atualidade, um ensino utilizando a perspectiva da educação bancária, mecânica, reprodutora dos conhecimentos sistematizados ao longo da história, dando ênfase na memorização, sem questionamentos, acrítica, arbitrária, imposta, sem relação com a vida, sem contextualização e sem significado (Freire, 2002; Brighente \& Mesquida, 2016). Diante disso, torna-se necessário que os professores rompam com esta realidade, buscando alternativas para que ocorra uma mudança e transformação do processo educacional, em que os estudantes sejam os protagonistas na construção do próprio conhecimento (Sá, Alves \& Costa, 2014; Urio et al., 2017). Assim, uma das formas de contribuir para essa mudança no cenário educacional é através do processo de formação continuada de professores. Conforme constata Pimentel, Oliveira e Maciel (2017), há uma ausência e deficiência, na formação continuada de professores e isso impossibilita um ensino de qualidade. Assim, Oliveira, Henkes e Strohschoen (2019) mostram ser essencial a participação dos professores em formações continuadas para que as aulas ministradas sejam perfeitamente exploradas, com mais argumentos, e o conhecimento, valiosamente formado.

Segundo Freire (1996), a formação continuada de professores tem como objetivo estimular e propulsionar a apropriação dos saberes docentes rumo a uma autonomia que o leve de fato a uma prática crítico-reflexiva. Ainda para o autor, “na formação permanente dos professores, o momento fundamental é o da reflexão crítica sobre a prática. É pensando criticamente sobre a prática de hoje ou de ontem que se pode melhorar a próxima prática" (Freire, 1996, p.39). De acordo com Oliveira, Frota e Martins (2016) o processo de formação de professores procura apresentar subsídios para que os mesmos possam abordar os mais diversos temas em suas aulas através de estratégias ainda pouco utilizadas e conhecidas. Dentro deste contexto, Oliveira, Frota e Martins (2016) e Rocha e Spohr (2016) destacam que os MCs são uma destas estratégias inovadoras e atuam como uma ferramenta mediadora do processo de aprendizagem de modo significativo, uma vez que focam em elementos da Teoria da Aprendizagem Significativa (TAS).

Como enfatiza Moreira (2010), a TAS foi proposta por David Paul Ausubel na década de 1960. Essa teoria do conhecimento aponta para uma aprendizagem profunda e significativa, onde a nova aprendizagem só acontece a partir dos conhecimentos prévios, também conhecidos como conceitos âncoras ou subsunçores (Moreira, 2015). Esses conhecimentos são pré-requisitos para acontecer a nova aprendizagem contendo sentido e significado para os aprendizes (Moreira, 2006, 2010). Contudo, no processo de ensino e aprendizagem, muitas vezes, o aprendiz, por algum fator externo não consegue assimilar os conteúdos trabalhados em sala de aula, favorecendo uma aprendizagem mecânica, com armazenamento literal, arbitrário, sem significado, sem compreensão, etc. (Moreira, 2010).

Assim, torna-se fundamental romper com tudo isso, através da compreensão, transferência de conhecimento, capacidade de explicar, descrever e enfrentar, situações novas, como apresentado na TAS (ver Ausubel, 2000). Nesse sentido, Moreira (2012) afirma que existem três condições básicas para ocorrência da aprendizagem significativa, como: 
conhecimentos prévios existentes e organizados na estrutura cognitiva do aprendiz, vontade e disposição do estudante para aprender, e material de estudo potencialmente significativo, entre os quais, se destacam os Mapas Conceituais.

Os MCs foram desenvolvidos pelo pesquisador norte-americano Joseph Novak, na década de 1970. Novak (1998) define os MCs como ferramentas que organizam, representam conhecimentos e expressam as relações significativas na forma de proposições. Caracterizações diversas sobre essa ferramenta didática, enquanto dispositivo gráfico são colocadas por outros autores, tais como, Moreira (2006), o qual destaca que, os MCs são diagramas que indicam relações entre conceitos; Tavares (2007), ao enfatizá-la como um estruturador do conhecimento; Gomes et al. (2010), indicando que ela corresponde a meios instrucionais que podem ser dinâmicos e flexíveis, e sempre em processo de construção de acordo com a visão do mapeador e/ou colaboradores e, Correia at al. (2016), os quais descrevem os MCs como um conjunto interconectado de proposições. Sendo um diagrama gráfico de grande valor educacional, Mousinho (2019) destacou que, a inserção do mapa conceitual como estratégia pedagógica tem se destacado nos processos de consolidação do conhecimento pela sua versatilidade ao promover transformações na estrutura cognitiva por estímulos adequados à aprendizagem.

Os MCs diferem dos outros organizadores gráficos (infográficos, mapas mentais, organogramas, etc.) por apresentar elementos constitutivos, como por exemplo, a questão focal e proposição (Correia at al., 2016). Conforme esses autores, a questão focal orienta a construção do Mapa Conceitual, já a proposição é o conjunto do conceito inicial, a seta indicando o sentido de leitura, constituída de uma frase de ligação, finalizando com conceito final. Assim, a relação conceitual deve ter alto grau de clareza semântica quando a frase de ligação apresenta um verbo (Correia at al., 2016). Segundo visto em Tavares (2007), existem alguns tipos de MCs, por exemplo, o de teia de aranha, fluxograma, sistema de entrada e saída, contudo, o que está em conformidade com os pressupostos de Novak e Gowin (1996), é o hierárquico. O tipo teia de aranha apresenta um conceito gerador central e os demais conceitos partem dele de forma radial, não se preocupando com a hierarquia dos conceitos, nem com suas relações conceituais. Já o fluxograma os conceitos estão dispostos de forma linear, explicitando o passo a passo de um processo de forma lógica e sequencial. O tipo sistema de entrada e saída, são similares aos fluxogramas no formato de sua organização com acréscimo da possibilidade de entrada e saída indicando as várias relações entre os conceitos. Já os hierárquicos, os conceitos estão dispostos segundo uma escala de importância do assunto que está sendo abordado (Tavares, 2007), além de poder apresentar ligações cruzadas ou cross links, que são interligações entre as sessões do mapa, ficando visível o domínio do mapeador sobre o tema (Novak \& Cañas, 2006).

Os MCs como um instrumento de ensino e aprendizagem contribuem para a promoção de experiências educativas que produzem reflexão e busca de compreensão dos conceitos ainda em construção e significação (Souza \& Boruchovitch, 2010). Nesse sentido, Correia et al. (2016) e Dias-da-Silva e Araújo-de-Almeida (2018) apontaram diversas utilizações de MCs, dispostos na literatura, para professores no processo de ensino e aprendizagem, tais como: planejamentos de aula; sistematização e revisão de conteúdos; ensinar e aprender novos tópicos; estimular hábitos de estudo, troca de ideia e trabalho em equipe; verificar a aprendizagem e facilitar o feedback de dúvidas pontuais, treinar interpretação e comunicação, entre outros. Assim, vários autores, como por exemplo, Kinchin at al. (2010), Novak e Cañas (2010), Moreira (2010, 2015), Aguiar e Correia (2013), Correia et al. (2016), Dias-da-Silva et al. (2019), Araújo-de-Almeida et al. (2020) e Góis, Góis e Barbosa (2021) destacam que o mapeamento conceitual constitui uma técnica de aprendizagem que vem sendo reforçada constantemente em sala de aula, atingindo amplos alcances locais e mundiais.

Apesar dos benefícios proporcionados pelos MCs no processo de ensino e aprendizagem, como enfatizam vários autores, é notório que, muitas das vezes, esta ferramenta é pouco conhecida e utilizada em sala de aula pelos professores da Educação Básica. Daí, surge a necessidade de ampliar o treino e uso dessa ferramenta, tanto no percurso da formação inicial de estudantes de graduação nos cursos de Licenciaturas; quanto no processo de capacitações dos professores direcionadas para o fomento de uso desse instrumento pedagógico em sala de aula. Destacam-se aqui tanto os aspectos teóricos e metodológicos no 
uso dessa ferramenta, quanto daqueles referentes à sua operacionalização por meio do CmapTools. Nesse sentido, Correia, Ballego e Nascimento (2020), destacam dificuldades que comumente são enfrentadas por grande parte dos professores no uso de MCs em sala de aula, como o tempo exigido para o treinamento e familiarização dos estudantes na técnica de mapeamento conceitual, como também o tempo para a correção dos mapas construídos pelos alunos. Dessa forma, os autores, apontam estratégias para minimizá-las, como por exemplo, colocar o professor no papel de mapeador, desenvolvendo atividades com os discentes, como por exemplo, a visualização sistêmica dos conteúdos, a elaboração de proposições a partir de um mapa conceitual parcialmente desenvolvido, a verificação do engajamento dos alunos com os materiais de estudo e a identificação de erros no mapa conceitual.

Dentro do contexto, teórico e metodológico, diversos trabalhos na literatura especializada discutem e exploram as potencialidades dos MCs na formação continuada dos professores, apresentando-os como ferramenta dinâmica e inovadora para a sala de aula, como podem ser visualizados em Oliveira, Frota e Martins (2011), Darroz et al. (2013), Góes e Boruchovitch (2017) e Almeida, Scheunemann e Lopes (2019).

No aspecto relacionado à operacionalização desses dispositivos gráficos, o uso do software CmapTools, desenvolvido pelo Institute for Human and Machine Cognition (IHMC) (Cañas et al., 2004), tem recebido atenção especial, principalmente em um momento de ampliação das habilidades digitais na área educacional. Vários autores, entre eles, Murga-Menoyo, Bautista-Cerro e Novo (2011), Marriott e Torres (2015), Pilger e Flores (2017) e Gewehr, Neide e Dellius (2018) trazem exemplos, abordando a utilização dessa ferramenta tecnológica do IHMC. Além do mais, o CmapTools é um software educacional de licença aberta que permite o mapeamento de conceitos para propiciar a aprendizagem significativa. Sendo aqui abordado como Recurso Educacional Digital (RED), vinculam-se, segundo Anjos e Silva (2018), como parte da sociedade da informação e da cultura digital. Nesse sentido, esse trabalho teve como objetivo avaliar e refletir sobre a aplicação de uma oficina de atualização pedagógica envolvendo MCs e CmapTools em momento de formação continuada de professores de ensino básico, habilitados em diferentes áreas do saber.

\section{Metodologia}

A presente pesquisa envolveu a aplicação e avaliação de uma oficina pedagógica intitulada "Mapas Conceituais utilizando CmapTools" desenvolvida com 50 professores da Secretaria Municipal de Educação da Prefeitura do Natal. Foi realizada no dia 31 de maio de 2021, no turno vespertino. Considerando as atividades desenvolvidas, a pesquisa pode ser caracterizada quanto a abordagem como qualitativa. Laville e Dionne (1999) dizem que na abordagem qualitativa se conserva a forma literal dos dados, demonstrando a subjetividade do pesquisador. Sendo eleita aqui como forma para obter os dados gerados da aplicação de questionários, antes e após a intervenção. Para o levantamento de dados, foram utilizados questionários, diário de observações e reflexões feitas pelo pesquisador no percurso de efetivação da oficina realizada.

A oficina supracitada ocorreu como parte curso de atualização pedagógica intitulado: "O Uso de Recursos Educacionais Digitais como Suporte Pedagógico para as Aulas Online (RED)", promovido pelo Núcleo de Tecnologia Educacional de Natal (NTE Natal). Esse evento pedagógico foi desenvolvido com carga horária de 2h30min (duas horas e meia), distribuídas em quatro momentos, tal como estruturados no Quadro 1, seguinte: 
Quadro 1 - Síntese dos momentos desenvolvidos na oficina.

\begin{tabular}{|c|c|c|c|}
\hline $\begin{array}{c}\text { MOMENTOS DA } \\
\text { AÇÃO DIDÁTICA }\end{array}$ & AÇÕES DESENVOLVIDAS & $\begin{array}{c}\text { RECURSOS } \\
\text { UTILIZADOS }\end{array}$ & TEMPO \\
\hline $1^{\circ}$ & Aplicação do questionário inicial & $\begin{array}{c}\text { Google Forms e } \\
\text { google Meet }\end{array}$ & 15 min \\
\hline $2^{\text {o }}$ & $\begin{array}{c}\text { Parte teórica: Exposição dialógica sobre a } \\
\text { Aprendizagem significativa, Mapas Conceituais e } \\
\text { CmapTools }\end{array}$ & $\begin{array}{c}\text { Google Slides e } \\
\text { Google Meet }\end{array}$ & $1 \mathrm{~h}$ \\
\hline $3^{\text {o }}$ & $\begin{array}{c}\text { Parte prática: Demonstrações sobre a } \\
\text { operacionalização do CmapTools e a construção de } \\
\text { um Mapa Conceitual colaborativo }\end{array}$ & $\begin{array}{c}\text { Software } \\
\text { CmapTools e } \\
\text { Google Meet }\end{array}$ & $1 \mathrm{~h}$ \\
\hline $4^{\circ}$ & Aplicação do questionário final & $\begin{array}{c}\text { Google Forms } e \\
\text { Google Meet }\end{array}$ & 15 min \\
\hline
\end{tabular}

Fonte: Sequência da ação didática desenvolvida pela primeira autora.

No primeiro momento ocorreu aplicação de um questionário inicial, desenvolvido no Google Forms, contendo 12 perguntas abertas e fechadas. Esse questionário teve como objetivo traçar um perfil dos participantes, bem como, sondar o conhecimento sobre MCs e sua utilização em sala de aula.

No segundo momento, utilizando-se do Google Slides, foi desenvolvido um espaço destinado aos aprofundamentos teóricos, abrangendo sobre: A) A Teoria da Aprendizagem Significativa de David Ausubel e suas relações com os MCs; B) MCs, enfatizando a organização, os elementos constitutivos e suas potencialidades didáticas em sala de aula, as quais podem ser visualizados na Figura 1, obtida a partir da obra A Teoria Subjacente aos Mapas Conceituais e como construí-los, de Novak \& Cañas (2010), uma edição traduzida da versão em inglês: The theory underlying concept maps and how to construct them (Novak \& Cañas, 2006, 2008). É importante destacar que, esta obra tem se evidenciado como uma das fontes básicas de leitura para mapeadores que seguem a linha novaquiana de interligar conceitos significativamente estruturados. Além do mais, este artigo também conta com a existência de uma versão em espanhol, La teoría subyacente a los mapas conceptuales y a cómo construirlos (Novak \& Cañas, 2006), somando, assim, mais um elemento de divulgação acessível, para quem deseja aprender e publicar, utilizando formas diversas de linguagens; C) Destaques ao tutorial Software CmapTools. 
Figura 1 - Mapa Conceitual mostrando as características dos Mapas Conceituais.

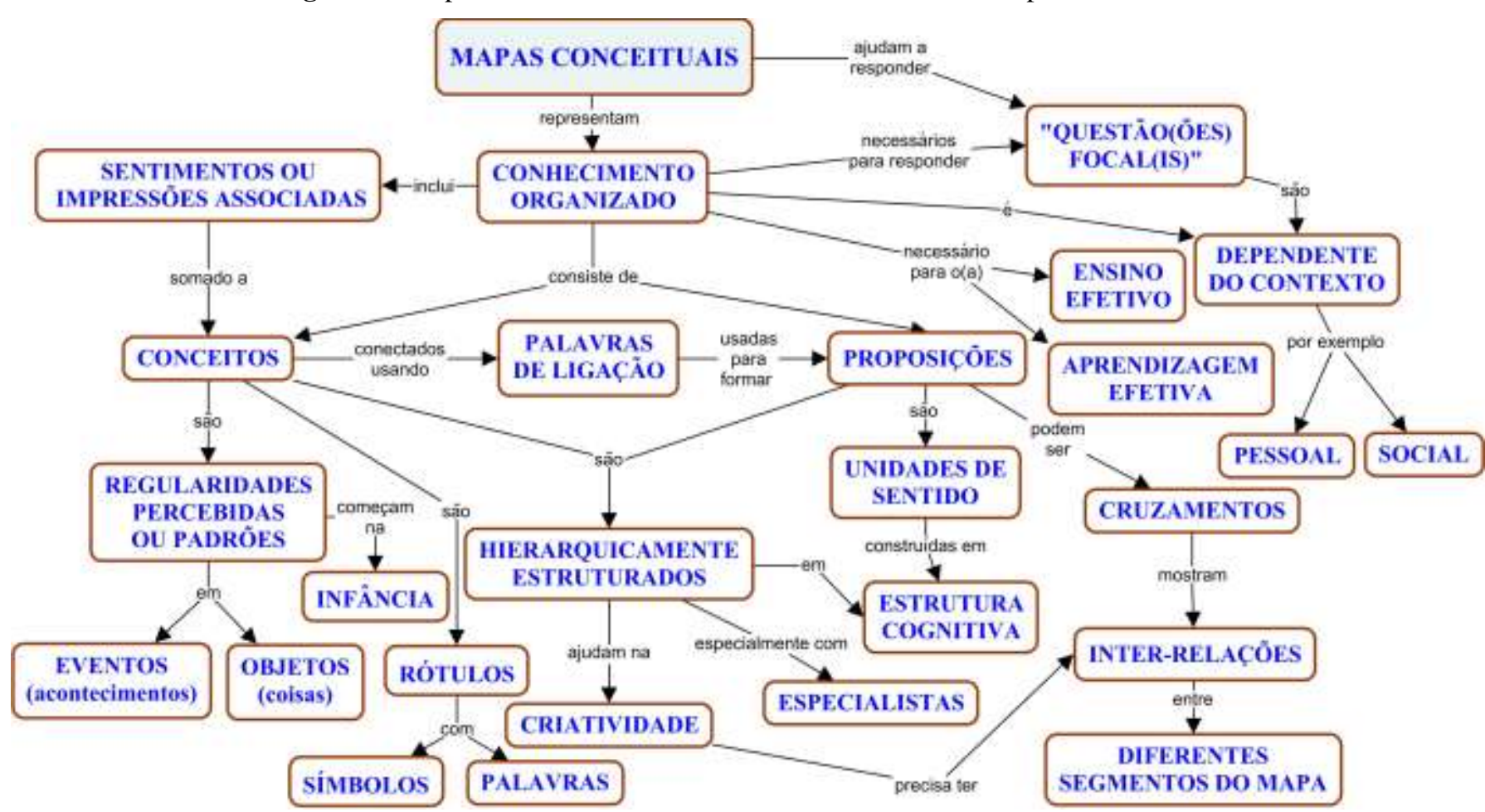

Fonte: Modificado de Novak e Cañas (2010, p. 10).

No que diz respeito ao terceiro momento da ação didática, realizou-se uma simulação, junto aos participantes, do passo a passo de como instalar o CmapTools, o software documentado por Cañas et al. (2004), como ferramenta para representação visual dos MCs. Como forma de ilustrar alguns detalhamentos sobre esse elemento de construção gráfica, Marriott \& Torres (2014) exemplificam, na Figura 2, que é possível implementar, por meio do CmapTool, desde recursos simples, tais como, modificar a aparência do mapa e da escrita, como também, tornar visíveis, sofisticados aspectos das pesquisas envolvendo conceitos diversos.

Posteriormente, explorou-se com os professores a janela inicial desse Software (abrir pastas, adicionar recursos, como imagens, vídeos, mapas conceituais, etc.), a criação de um novo Mapa Conceitual e seus recursos (adicionar conceitos, termos de ligação e janela de estilos). Em seguida, visando aplicar os conhecimentos sobre a técnica de mapeamento conceitual adquiridos na ação didática, escolheu-se um tema familiar a todos os participantes e, construiu-se, de forma colaborativa, um mapa conceitual sobre o tema COVID-19, cujos conhecimentos prévios dos cursistas foram mais facilmente acessados, devido ao grande número de informações veiculadas diariamente sobre a pandemia do SARS-CoV-2, desde o ano de 2020.

No quarto e último momento, foi aplicado um questionário final contendo 5 perguntas gerais, sobre a experiência vivenciada, incluindo questões abertas e fechadas. Este questionário avaliativo também foi estruturado e disponibilizado para os participantes, pelo Google Forms, esse questionário teve como objetivo levantar a perspectiva dos participantes sobre o desenvolvimento e contribuições da oficina para a formação destes, bem como, pretensões de aprofundamentos sobre os Mapas Conceituais e aplicações em sala de aula.

Diante disso, a oficina foi avaliada utilizando-se de recortes dos dados obtidos através do questionário inicial e questionário final. Para isso, as respostas dos questionários foram exportadas para planilhas do Microsoft Office Excel 2016, onde os dados foram categorizados e interpretados. 
Figura 2 - Mapa Conceitual ilustrando graficamente considerações sobre o CmapTools.

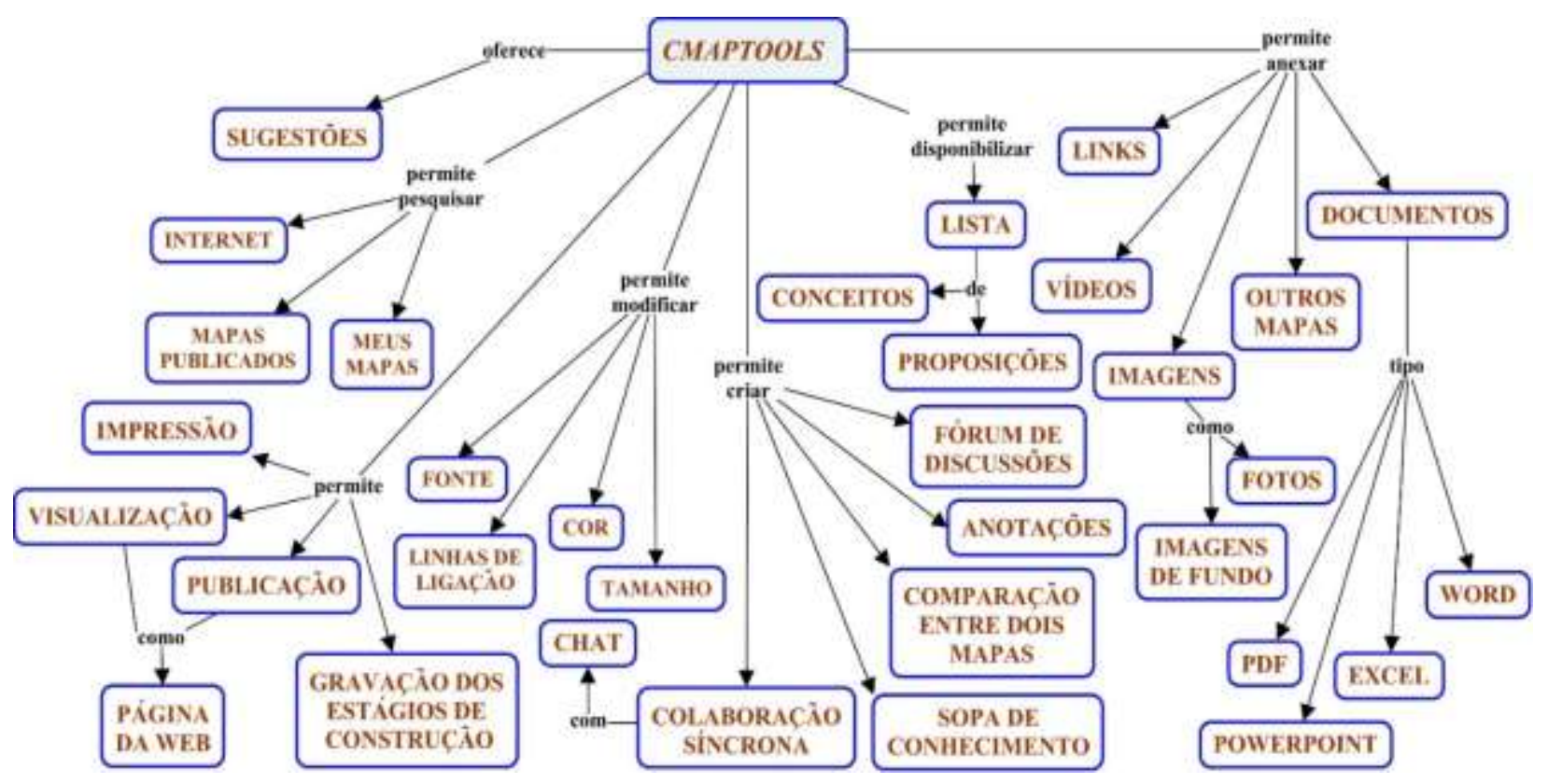

Fonte: Modificado de Marriott e Torres. (2015, p. 195).

\section{Resultados e Discussão}

Dos 50 professores que se inscreveram na oficina, 25 assinalaram que lecionam na Educação Infantil, 14 no Ensino Fundamental I, 01 do Ensino Fundamental II, 01 leciona tanto no Ensino Fundamental II como no Ensino Médio, 01 assegurou ser Mediador de Leitura, 02 coordenadores pedagógicos e 01 Gestor Pedagógico (Figura 3). Quanto à formação dos participantes 35 participantes têm Pós-Graduação Latu Sensu, 2 possuem Pós-Graduação Strictu Sensu, e 8 apresentam apenas graduação.

Figura 3 - Cargo/Função dos participantes da oficina.

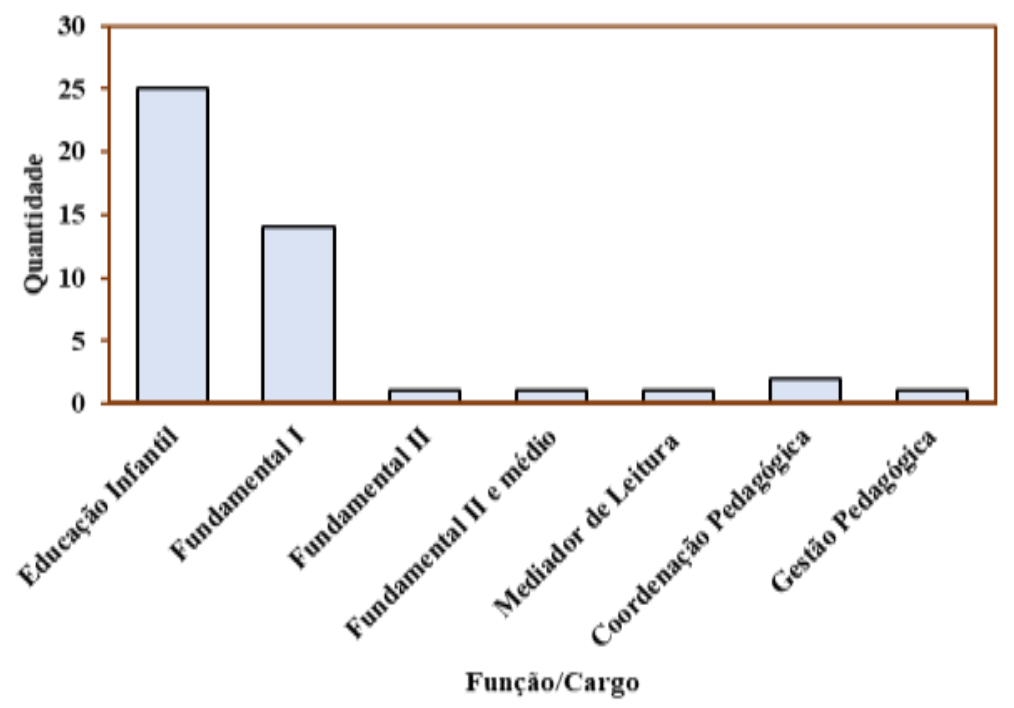

Fonte: Autores (2021).

Apesar de ocorrer a participação de 50 professores na oficina, foi obtido no questionário inicial 45 respostas, e no questionário final 34 respostas. As quais serão discutidas a seguir. 


\subsection{Questionário inicial}

Quando os participantes da oficina foram perguntados "Você conhece a ferramenta gráfica, Mapas Conceituais?", 12 participantes afirmaram que "Sim" e 33 afirmaram que "Não" (Figura 4).

Figura 4 - Quantidade de participantes e indicaram conhecer ou desconhecer os MCs

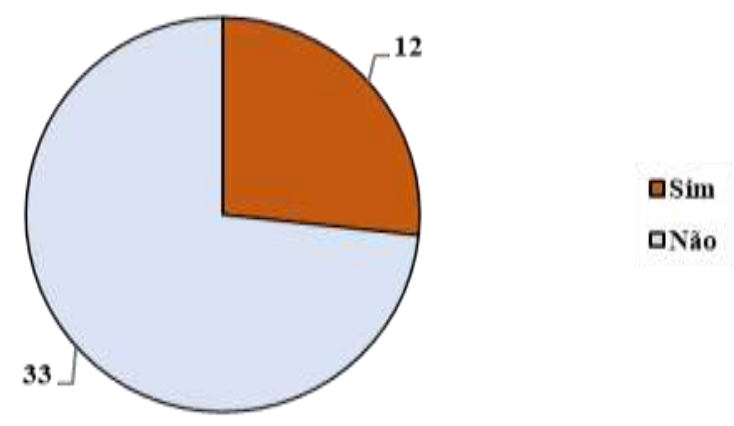

Fonte: Autores (2021).

Aos serem indagados "Você faz ou já fez uso de Mapas Conceituais?", 05 dos participantes assinalaram que "Sim" e 40 responderam que "Não" (Figura 5).

Figura 5 - Quantidade de participantes que reportaram fazer ou ter feito uso MCs em sala de aula.

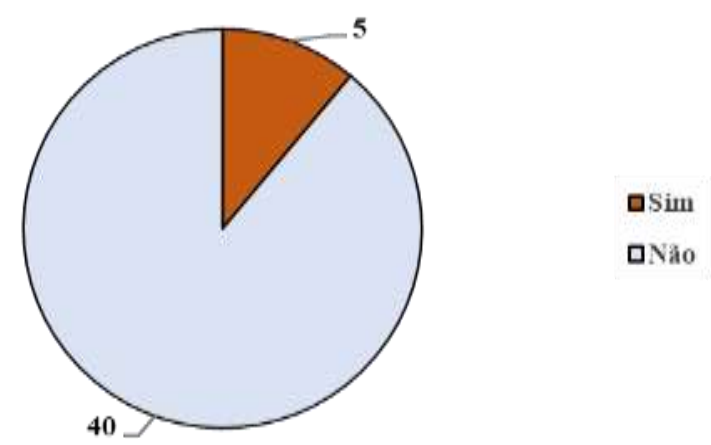

Fonte: Autores (2021).

Esses dados, difíceis de serem anunciados, revelam que, embora os MCs sejam uma ferramenta bem consolidada no ambiente educacional, em diversos contextos, níveis de ensino e áreas do conhecimento, conforme apontado por Kinchin (2014), revelam que o grupo professores, ali reunidos, desconheciam ou não eram proficientes para utilizarem essa ferramenta em suas salas de aula.

Porém, ao observar as Figuras 2 e 3, é possível perceber que um pequeno grupo de participantes informaram que já conheciam essa ferramenta. Contudo, por meio de relatos e discussões no decorrer da oficina, percebe-se que muitos destes mostraram-se, inicialmente, confusos quanto aos MCs em detrimento de outros organizados gráficos. Os participantes também desconheciam os fundamentos teóricos básicos para o uso dos MCs na prática docente. Esse fato, é intrigante e levanta pontos relevantes para a reflexão: na prática docente dos professores participantes que afirmaram conhecer e utilizar os MCs, como essa ferramenta foi explorada? Tratava-se realmente de MCs ou outra ferramenta gráfica similar? O desconhecimento da fundamentação teórica da TAS e MCs levaram ao "uso ingênuo" dessa ferramenta? 
De acordo com Aguiar et al. (2009), muitas das dificuldades observadas com a utilização efetiva do mapeamento conceitual em sala de aula derivam, pelo menos em parte, do emprego inadequado da técnica, do treinamento inadequado dos usuários e formadores, além da falta de reconhecimento da importância dos fundamentos teóricos dessa técnica. Nesse contexto, o uso ingênuo dos MCs pode resultar nos seguintes acontecimentos: a) o professor opta pelo uso dos MCs para mudar a dinâmica tradicional das aulas expositivas; c) o professor tem dificuldades de avaliar a grande quantidade de MCs produzidos pelos discentes, visto que o livro didático não apresenta um gabarito para corrigi-los; d) o professor não oferece um feedback adequado aos alunos e a avaliação restringe-se a contabilidade burocrática dos alunos que cumpriram essa tarefa; e) o professor não encontra na sua prática docente os benefícios prometidos pelo mapeamento conceitual, levando-o a não utilizar mais essa técnica em sala de aula" (Correia, Silva \& Romano Júnior, 2010).

\subsection{Questionário final}

Entre os participantes da pesquisa 34 responderam ao questionário final aplicado após as atividades da oficina. Quando foram perguntados "Você considera os Mapas Conceituais uma ferramenta capaz de produzir situações de ensino e aprendizagem?" por unanimidade, todos os participantes responderam que "Sim". Essa realidade vem mostrar que os participantes entenderam que os MCs são potencialmente significativos para suas atividades docentes. Dados semelhantes foram encontrados por Almeida, Scheunemann e Lopes (2019), que ao investigar a visão dos professores da educação básica de uma escola da rede Municipal de Sapucaia do Sul, Rio Grande do Sul, sobre a viabilidade do uso dos MCs em sala de aula, todos os docentes asseguraram positivamente, e apontaram diversos benefícios dos MCs, como estimular a participação dos estudantes, tornar a aprendizagem lúdica e dinâmica, organizar os conhecimentos obtidos, dentre outros.

Já ao serem indagados "Avalie a experiência de aprendizado com a oficina Mapas Conceituais utilizando CmapTools", 31 professores afirmaram que a oficina "Contribuiu muito para o meu aprendizado", e apenas 3 disseram que "Contribuiu pouco para meu aprendizado" (Figura 6). Este retorno positivo dos professores participantes enfatizam a importância deste tipo de formação, a qual proporcionou subsídios para um melhor entendimento da Teoria da Aprendizagem Significativa e fundamentos teórico-práticos sobre os MCs, tornando-os aptos a utilizá-los em sala de aula. Este aspecto é importante, pois, como afirma Bühler (2013, p. 145) "O bom professor deve revelar em sua prática docente seu comprometimento com a teoria e a tradução desta para a realidade".

Figura 6 - Avaliação dos participantes sobre as contribuições da ação didática com MCs e CmapTools.
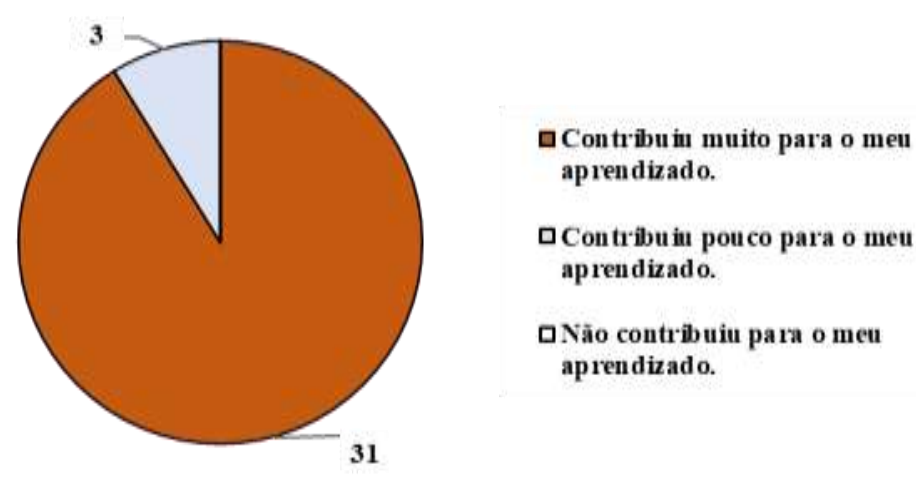

Fonte: Autores (2021).

Já a pergunta "A partir da vivência com a atividade, você indicaria o uso de Mapas Conceituais para algum professor?" todos os respondentes assinalaram que "Sim". Esses dados reforçam as contribuições da oficina para a formação dos professores quanto ao uso dos MCs, os quais, tendo conhecimento sobre as potencialidades dessa ferramenta 
para a aprendizagem dos estudantes, demonstraram interesses em indica-la para outros profissionais de educação, para que esses também possam aplica-la em suas práticas pedagógicas.

No momento que foram questionados que "Teria interesse de estudar mais possibilidades sobre Mapas Conceituais em outra oficina?" 32 participantes confirmaram que "Sim", e 2 destes "Não" demonstraram interesse (Figura 7).

Figura 7 - Revelação de interesses dos professores em participar de outras ações sobre MCs.

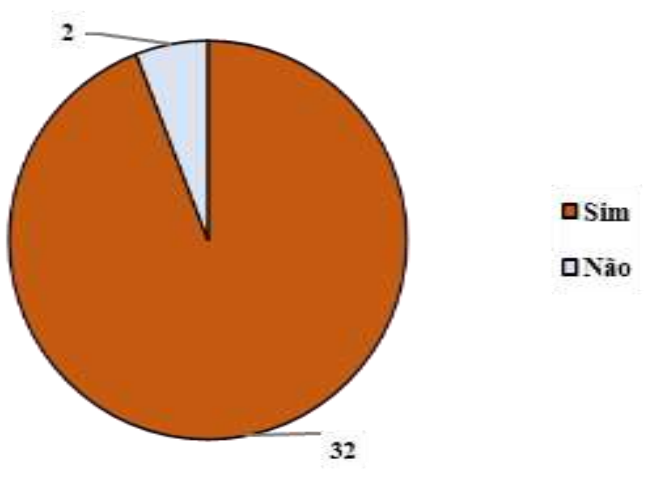

Fonte: Autores (2021).

Percebe-se a partir desses dados que os participantes demonstraram sentir necessidade de mais aprofundamentos sobre os MCs na sua formação continuada. Diante disso, acredita-se que os professores ao adquirem mais conhecimento sobre essa ferramenta, terão mais embasamento e motivação para sua utilização em sala de aula. Diante de tudo o que foi exposto percebe-se a deficiência na formação dos educadores, o que Darroz et al. (2013) vem ratificar em sua pesquisa sobre as dificuldades enfrentadas pelos professores com lacunas conceituais em sua formação, e influenciam diretamente no agir docente e pedagógico trazendo problemas sérios para o ensino e aprendizagem, como destacados por Silveira (2004), Langhi e Nardi (2007), Oliveira, Frota e Martins (2011).

\section{Considerações Finais}

Por meio dos resultados obtidos e analisados e, das reflexões realizadas em torno da ação didática com os mapas conceituais, junto aos professores cursistas, evidencia-se que, a temática promoveu atualizações pedagógicas e fomentou perspectivas de mudanças para a sala de aula. A demonstração de interesse pessoal dos participantes e, do reconhecimento expresso que, essa ferramenta gráfica deve ser ampliada para outros colegas professores, é um indicativo já confirmado, da relevância e benefícios proporcionados pelo uso dos MCs no processo de ensino e aprendizagem.

Considera-se que, a pouca vivência dos participantes com a técnica de mapeamento conceitual, faz com que sejam reveladas ideias e concepções errôneas acerca desse dispositivo, percebidas quando comparado com outros organizadores gráficos, como por exemplo, mapas mentais, infográficos, organogramas, entre outros. Nesse sentido, os MCs constituem um elemento de competência pedagógica, a ser trabalhado desde a formação inicial de professores, como também na formação continuada dos profissionais de ensino. Enquanto vivência conceitual em torno de um conteúdo de estudo direcionado a cursos de formação continuada, destaca-se que, lidar com um público mais diversificado, exige-se focar em temas atualizados e de conhecimento comum, para motivar a participação e o envolvimento de todos em um tema que permita negociar significados de forma colaborativa.

Ao final da oficina, muitos demonstraram interesse em obter, em outros momentos de aprendizagem, mais aprofundamentos teóricos e práticos sobre os MCs. Diante disto, recomenda-se, que sejam efetivados outros momentos de 
formação e capacitação direcionadas aos professores, de preferência com uma carga horária mais ampliada, para que estes obtenham mais conhecimentos e experiências com os MCs utilizando a ferramenta CmapTool para sua construção.

Considerando-se que, durante a pandemia do SARS-CoV-2, no início de março de 2020, o NTE, ao vencer o desafio de reestruturar alguns cursos para o formato totalmente online, nas interações síncronas e assíncronas para auxiliar os professores do município de Natal, em suas aulas remotas, promoveu-se, de forma ágil, atualizações pedagógicas para o corpo docente. A exemplo, o Curso: "O uso de Recursos Educacionais Digitais (RED)" como suporte pedagógico para as aulas online, destinado a professores e coordenadores pedagógicos da educação infantil, anos iniciais e finais do fundamental. O conteúdo, abordando a importância da cultural digital no que se refere a utilização pedagógica de recursos digitais abertos (como licenças CC), o (re)uso e produção de recursos educacionais digitais pensado para o planejamento e avaliação de atividades desenvolvidas durante as aulas remotas ampliou o objetivo de fornecer elementos para compreender, utilizar e criar recursos educacionais digitais como instrumento cultural de aprendizagem do aluno.

Essa formação contribuiu para produção e publicação de recursos educacionais digitais no sentido de incorporar no cotidiano do professor a cultura digital com uso das Tecnologias Digitais da Comunicação e Informação (TDIC). Nesse sentido, almeja-se ampliar a oficina em sua carga horária, bem como, nos conteúdos teóricos e práticos sobre os MCs. E ainda, proporcionar uma aproximação mais significativa dos professores com o CmapTools, uma ferramenta digital de uso prático, na sua formação, para que os MCs tenham usos mais ampliados, promovendo assim, melhorias da qualidade do ensino e da aprendizagem dos discentes.

\section{Agradecimentos}

Agradeçemos ao Núcleo de Tecnologia Educacional de Natal (NTE Natal) da Secretaria Municipal de Educação da Prefeitura do Natal, bem como, aos professores que participaram ativamente na resolução e discussões durante a oficina dentro do curso "O Uso de Recursos Educacionais Digitais como Suporte Pedagógico para as Aulas Online (RED)".

Expressamos nossa gratidão ao curso de Pós Graduação em Ensino de Ciências Naturais e Matemática (PPGECNM), do Centro de Ciências Exatas e da Terra da Universidade Federal do Rio Grande do Norte (UFRN), pelo fomento à técnica de mapeamento conceitual ao ser contemplada na ementa de Componentes Curriculares ministrados para o respectivo curso, com perpectiva de receber estudantes graduados externos, por meio de seleção, em caráter especial, bem como, pelo engajamento de professores diversos que orientam estudantes em sua formação continuada, em nível de mestrado, nessa temática pedagógica.

\section{Referências}

Aguiar, J. G. et al. (2009). Avaliação da proficiência em mapeamento conceitual. In: Encontro Nacional de Pesquisa em Educação em Ciências, 7, 2009. Atas do ENPEC. VII ENPEC.

Aguiar, J. G. \& Correia, P. R. M. (2013). Como fazer bons mapas conceituais? Estabelecendo parâmetros de referências e propondo atividades de treinamento. Revista Brasileira de Pesquisa em Educação em Ciências, 13(2),141-157.

Almeida, C. M. M., Scheunemann, C. M. B. \& Lopes, P. T. C. (2019). Formação continuada para professores em serviço do Ensino Fundamental Séries Iniciais: Aprendizagem Significativa e mapas conceituais. Revista Brasileira de Ensino de Ciências e Matemática, 2(2),12-21.

Anjos, A. M. \& Silva, G. E. G. (2018). Tecnologias Digitais da Informação e da Comunicação (TDIC) na Educação. Secretaria de Tecnologia Educacional. Universidade do Mato Grosso do Sul. <https:/www.educapes.capes.gov.br/bitstream/capes/429662/2/Tecnologias\%20DigC3\%A3o\%20\%28TDIC\%29\%20n a\%20Educa\%C3\%A7\%C3\%A3o.pdf>

Araújo-de-Almeida, E. et al. (2020). Elaboração e aprimoramento de mapas conceituais sobre táxons zoológicos. Brazilian Journal of Development, 6(10), $83651-83672$.

Ausubel, D. P. (2000). The acquisition and retention of knowledge. Kluwer Academic Publishers. 
Brighente, M. F. \& Mesquida, P. (2016). Paulo Freire: da denúncia da educação bancária ao anúncio de uma pedagogia libertadora. Pro-Posições, 27(1), 155177.

Bühler, C. (2013). O bom professor: referências que o constituem. Sinodal.

Cañas, A. J. et al. (2004). CmapTools: A knowledge modeling and sharing environment. In: Cañas, J. D. Novak, J. D. \& Gonzalez, F. M. (Eds.). Concept Maps: Theory, Methodology, Technology, Proceedings of the 1st International Conference on Concept Mapping. Universidad Publica de Navarra, 125-133.

Correia, P. R. M. et al. (2016). Por que vale a pena usar mapas conceituais no ensino superior? Revista Graduação USP, 1(1), 1-12.

Correia, P. R. M., Silva, A. C. D. \& Romano Junior, J. G. (2010). Mapas conceituais como ferramenta de avaliação na sala de aula. Revista Brasileira de Ensino de Física, 32(4), 44021-44028.

Correia, P. R. M., Ballego, R. S. \& Nascimento, T. S. (2020). Os professores podem fazer mapas conceituais? Sim, eles devem! Revista de Graduação USP, 4(1), 29-39.

Dias-da-Silva, C. D. \& Araújo-de-Almeida, E. (2018). Sugestões didáticas para exploração de mapas conceituais na formação pedagógica: evidenciando conteúdos biológicos. Produto Educacional, PPGECNM-UFRN. <https://repositorio.ufrn.br/bitstream/123456789/26 270/4/ProdutoEducaciona 1_Silva_2018.pdf>.

Dias-da-Silva, C. D. et al. (2019). Motivações de estudantes para aprendizagem em Zoologia por meio de mapas conceituais. Brazilian Journal of Development, 5(20), 2675-26734.

Dutra, I. M. et al. (2014). Blog, wiki e mapas conceituais digitais no desenvolvimento de projetos de aprendizagem com alunos do ensino fundamental. In: Flores E. A. P. et al. (Orgs.). Tecnologias na Educação: ensinando e aprendendo com as TIC - Uma proposta para a Educação do Campo. Universidade Federal do Pampa Campus Jaguarão, p. 99-109.

Farias; Q. C. \& Torres, E. C. (2014). O uso do software educacional CmapTools na formação continuada dos professores de geografia. Cadernos PDE, 2(1)435 .

Freire, P. (2002). Pedagogia da autonomia. Paz e Terra.

Freire, P. (1996). Pedagogia da autonomia: saberes necessários à prática educativa. (37a ed.), Paz e Terra.

Gewehr, D., Neide, I. G. \& Dellius, M. M. (2018). Mapas conceituais com CmapTools: uma metodologia ativa de ensino e aprendizagem para nativos digitais, Educitec, 4(7), 152-165.

Góes, N. M. \& Boruchovitch, E. (2017). O uso do mapa conceitual na formação de futuros professores em disciplina de estágio supervisionado: um relato de experiência. Psicologia Ensino \& Formação, 8(2), 53-62.

Góis, A. R. S., Góis, C. G. S. \& Barbosa, P. F. C. (2021). Conceptual map in face-to-face teaching during the coronavirus pandemic: experience report. Research, Society and Development, 10(3), 1-7.

Gomes, A. P. et al. (2010). Ensino de ciências: dialogando com David Ausubel. Revista Ciências \& Ideias, 1(1), 23-31.

Kinchin, I. M. (2014). Concept mapping as a learning tool in higher education: a critical analysis of recent reviews. The Journal of Continuing Higher Education, 62(1), 39-49.

Langhi, R \& Nardi, R. (2007). Ensino de Astronomia: Erros conceituais mais comuns presente em livros didáticos de ciência. Caderno Brasileiro de Ensino Física, 24(1), 87-111.

Laville, C. \& Dionne, J. (1999). A construção do saber: manual de metodologia da pesquisa em ciências humanas. Porto Alegre: Artmed: Belo Horizonte: Editora UFMQ.

Marriott, R., \& Torres, P. L. (2015). Mapas conceituais uma ferramenta para a construção de uma cartografia do conhecimento. In: Torres, P. L. Complexidade: redes e conexões na produção do conhecimento. Curitiba: SENAR-PR.

Moreira, M. A. (2015). Aprendizagem significativa, organizadores prévios, mapas conceituais, diagramas $V$ e unidades de ensino potencialmente significativas. Editora UFRGS.

Moreira, M. A. (2010). Mapas conceituais como instrumentos para promover a diferenciação conceitual progressiva e a reconciliação integrativa. Ciência e Cultura, 32(4), 474-479.

Moreira, M. A. (2012). Mapas conceituais e aprendizagem significativa (concept maps and meaningful learning). Aprendizagem significativa, organizadores prévios, mapas conceituais, digramas $V$ e Unidades de ensino potencialmente significativas, Editora UFRGS. 
Moreira, M. A. (2006). Mapas conceituais e diagramas V. Editora UFRGS.

Mousinho, S. H. (2019). A utilização dos mapas conceituais para a construção dos conceitos no processo de aprendizagem. EaD \& Tecnologias Digitais na Educação, 7(9), 40-51.

Novak, J. D. A. (1998). Criar e utilizar o conhecimento: mapas conceptuais como ferramentas de facilitação nas escolas e empresas. Lisboa: Plátano edições técnicas.

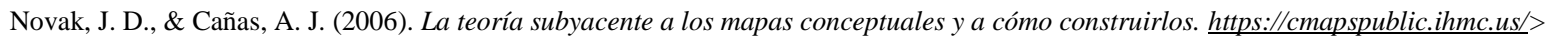

Novak, J. D., \& Cañas, A. J (2006). The theory underlying concept maps and how to construct them. Technical Report IHMC CmapTools, Florida Institute for Human and Machine Cognition. http://cmap.ihmc.us/Publications/ResearchPapers/TheoryUnderlyingConceptMaps.pdf,

Novak, J. D., \& Cañas, A. J. (2008). The theory underlying concept maps and how to construct and use them. Pensacola, FL: Institute for Human and Machine Cognition. http://cmap.ihmc.us/Publications/ResearchPapers/TheoryCmaps/TheoryUnderlyingC onceptMaps.htm,

Novak, J. D., \& Cañas, A. J. (2010). A teoria subjacente aos mapas conceituais e como elaborá-los e usá-los. Práxis educativa, 5(1), 9-29.

Novak, J. D., \& Gowin, D. B. (1996). Aprender a aprender. Plátano Edições. Técnicas.

Murga-Menoyo M. A., Bautista-Cerro M. J. \& Novo M. (2011). Mapas conceptuales con cmap tools en la enseñanza universitaria de la educación ambiental: estudio de caso en la UNED. Enseñanza de las ciencias: revista de investigación y experiencias didácticas, 29(1), 47-59.

Oliveira, M. M.; Frota P. R. O. \& Martins M. C. (2011). A teoria da aprendizagem significativa de Ausubel e os mapas conceituais de Novak na formação de professores pedagogos. Colóquio Internacional de Educação, 1(1), 1-10.

Oliveira, A. M., Henkes, S. B. R., \& Strohschoen, A. A. G. (2019). Mapa conceitual e World Café: ressignificando o ensino de ciências pela argumentação. Research, Society and Development, 8(3), 13.

Pilger, C. V. \& Flores, M. L. P. (2017). Ferramentas de autoria: CMap Tools: uma proposta de avaliação do processo de ensino e aprendizagem. In: Tarouco, L. M. R.; Abreu, C. S. (Orgs.). Mídias na Educação: a pedagogia e a tecnologia subjacentes. Editora UFRGS, 9-27.

Pimentel, P. M. S., Oliveira, M. V. P., \& Maciel, E. M. (2017). Teoria e prática no âmbito do ensino médio: análise de casos no Piauí e Ceará para o ensino de biologia. REnCiMa, 8(3), 158-173.

Rocha, C. E. S., \& Spohr, C. B. (2016). O uso de mapas conceituais como instrumento didático para identificar indícios de aprendizagem significativa em diferentes níveis de ensino. Investigações em Ensino de Ciências, 21(3), 23-52.

Sá, S. O., Alves, M. P., \& Costa, A. P. (2014). A avaliação formativa no ensino superior: o contributo do feedback interativo e construtivo na aprendizagem ativa dos estudantes. Comunicação \& Informação, 17(2), 55-69.

Silveira, F. P. R. A. (2004). A aprendizagem significativa na formação de professores de biologia: o uso de mapas conceituais. Revista Brasileira de Pesquisa em Educação em Ciências, 4(3), 29-41.

Souza, N. A. D., \& Boruchovitch, E. (2010). Mapas conceituais: estratégia de ensino/aprendizagem e ferramenta avaliativa. Educação em Revista, 26, 195217.

Tavares, R. (2007). Construindo mapas conceituais. Ciências \& cognição, 12(1), 72-85.

Urio, Â. et al. (2017). Desafios na utilização de estratégias para aprendizagem ativa com estudantes em uma escola pública. Rev. enferm. UFPE on line, 11 (12) 4866-4874. 